\title{
INHERITANCE OF BALDNESS
}

\section{Various Patterns Due to Heredity and Sometimes Present at Birth-A Sex-limited Character-Dominant in Man-Women Not Bald Unless They Inherit Tendency from Both Parents ${ }^{1}$}

\author{
DOROTHY OSBORN \\ Ohio State University, Columbus, Ohio
}

$\mathrm{T}$ HERE are several distinct patterns of baldness. They vary in extent from the small spot, not uncommon, to entire baldness which is exceptional. Among the most common patterns are complete baldness on the top of the head, that irrvolving only the crown, that giving the appearance of an extremely high forehead, and that covering the top and back of the head. The hair associated with baldness may be thin, normal or heavy.

Many theories have been advanced as to the cause of baldness. Some of these are diseases of the scalp, ill health, pressure of tight hatbands on the scalp, and heredity. Recently an article appeared in a popular magazine declaring that baldness is entirely due to the indiscriminate wearing of hats, not necessarily tight. Not baldness itself, but the shape of the head is inherited and in wearing hats the consequent pressure on the blood vessels nourishing the scalp causes the loss of hair. The main argument in support of this theory was that women never become bald.

In collecting data for this paper all types of hair were recorded as thin, normal or heavy. Questions were also asked as to how long heavy hair was retained, the pattern and time of appearance of baldness if present, the kind of hat worn, and what was used to prevent baldness. The results show that baldness is undoubtedly hereditary.

Two families with exceptionally heavy hair were traced, and no baldness could be found in either one. Ordinary tight hats had been worn by the men, which had not affected the persistence of the hair. In case the hair was exceptionally heavy in youth more than a normal amount was retained to an advanced age.

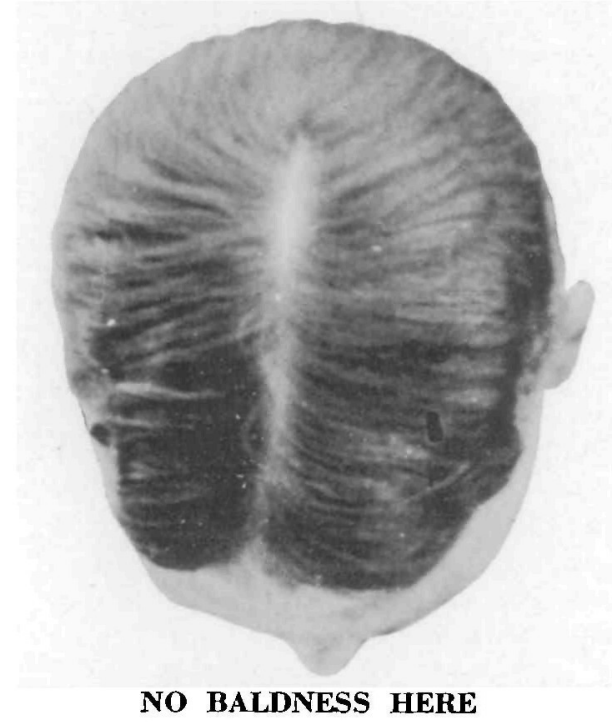

A head of thick, fine hair, at the age of 33. Father of this subject is now 61 years old with abundant hair. Both father and son wear tight hats. There is no baldness in the family history. (Fig. 1.)

In the first chart, III 3 had very poor health, but until her death at thirty-five her hair was always remarkably heavy. Ill health had had no noticeable effect. Her niece, IV 12, now twenty years old, who originally

1 Contribution No. 48 from the Department of Zoology and Entomology, O. S. U. This work was done in a course in genetics under the direction of Prof. William M. Barrows. 


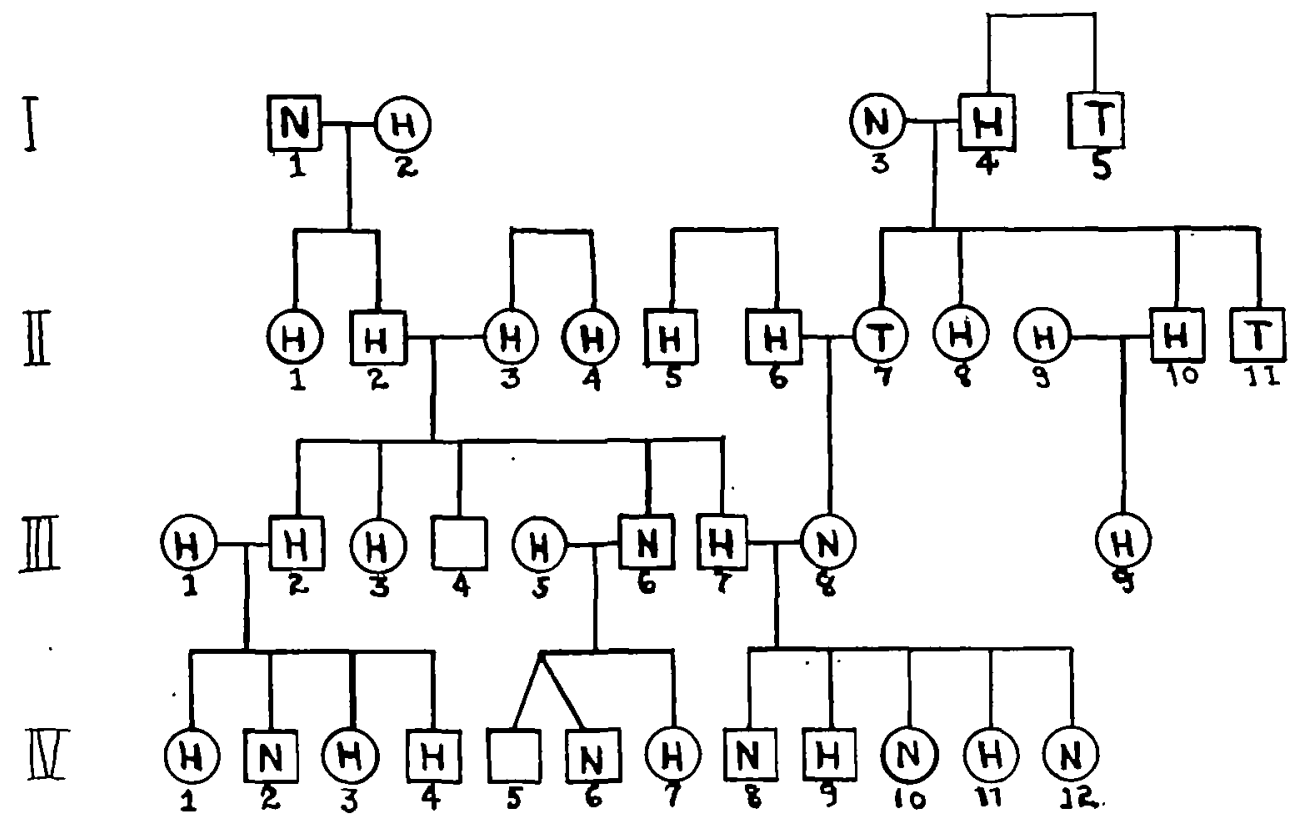

A FAMILY IN WHICH NO BALDNESS HAS APPEARED (Chart 1)

Squares represent males and circles females; solid black symbols (used in subsequent charts, but not in this one) indicate baldness. $\mathrm{H}=$ heavy hair, $\mathrm{N}=\mathrm{a}$ normal amount, $\mathrm{T}=$ thin hair, ? indicates uncertainty as to baldness, due to lack of information. Particulars as to the individuals on the above chart follow:

Generation I. I 1 had at least a normal amount of hair, and it may have been heavy. I 2 had heavy hair, and many members of her family had exceptionally heavy hair. I 3 had at least a normal amount of hair, and I 4 probably heavy. I 5 had thin hair.

Generation II. II 1, II 2, II 3, II 4, II 5, and II 6 had heavy hair, and retained same throughout life. II 7 has thin hair, is now eighty-nine, and retains her normal amount of hair. II 8 , II 9 , and II 10 had heavy hair. II 11 had thin hair.

Generation III. III 1 had heavy hair. III 2 has very hoavy hair. III 2 had very heavy hair, and although in poor health for a number of years, retained it until her death at thirty-five. III 4 died at the age of thirteen which makes data doubtful. III 5 and III 6 both have heavy hair. III. 7 has exceptionally heavy hair and retains same at sixty years of age. III 8 has about normal hair. III 9 had heavy hair.

Generation IV. IV 1, IV 3, and IV 4 have very heavy hair. IV 2 has not much more than a normal amount. IV 5 died in infancy. IV 6 has not much more than a normal amount. IV 7 has exceptionally heavy hair. IV 8 has about the normal amount. IV 9 has extremely heavy hair, very similar to his father's. IV 10 has slightly less than normal. IV 11 has very heavy hair, and IV 12 has less than a normal amount, due to illness. (Fig. 2.)

had a normal amount of hair, has lost much through poor health. In the other family studied, one man, now sixty, has been in very poor health for a number of years, but there has been no noticeable effect on his hair, which is very heavy and coarse.

Returning to chart 1 , II 7 and I 5 both had very thin fine hair, but retained it until very late in life. I 5 died at ninety-three and II 7 is now eighty-nine. Her husband, II 6 , had heavy coarse hair and their daughter,
III 8 , has a normal amount of moderately fine hair. The husband of III 8 , now sixty, has exceptionally heavy coarse hair, common in his family. The children of this mating show an interesting variety of amounts and textures of hair. IV 8 has a normal amount of moderately fine hair; IV 9 has exceptionally heavy, coarse hair like his father's; IV 10 has not quite a normal amount of moderately coarse hair; IV 11 has very heavy, fine hair, and IV 12 has rather thin fine hair. 


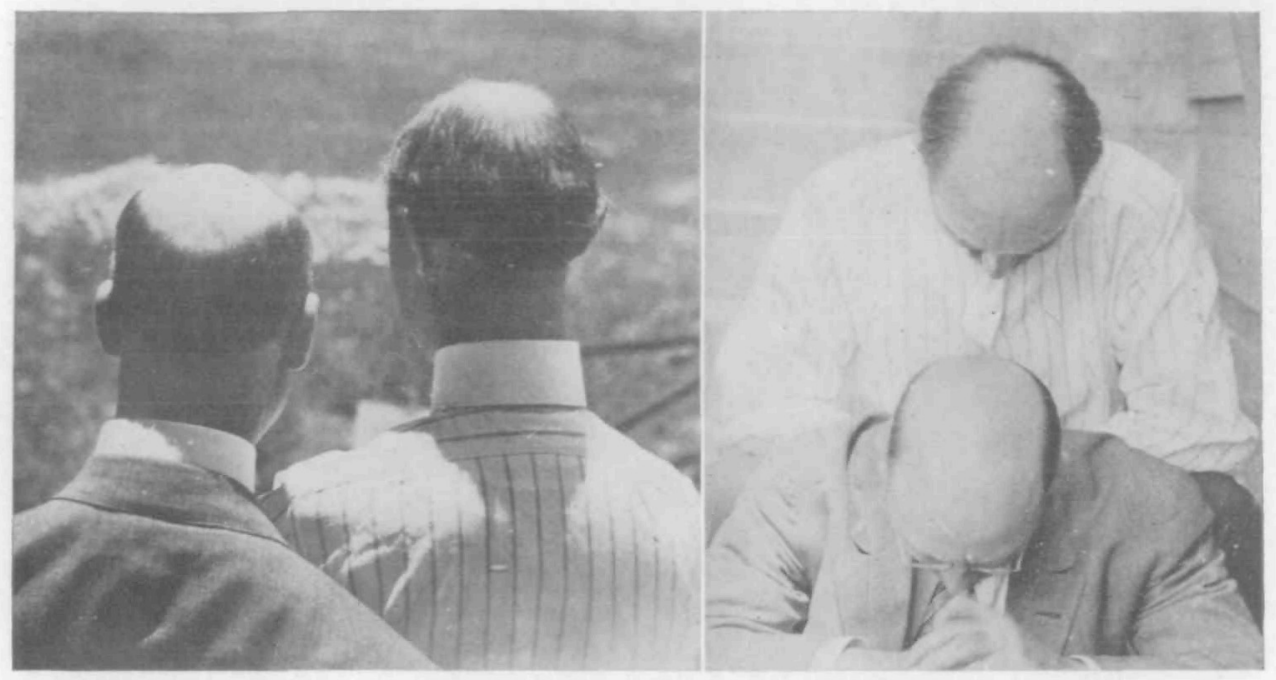

TWO CASES OF PATTERN-BALDNESS

The same individuals are shown in each picture. The man at the right (upper, in the second picture) had heavy, coarse, curly hair until twenty years ago, when he began to lose it very gradually. His father had the same pattern of baldness; his mother's family had thin hair but no baldness. The lower individual has thin, straight hair; baldness appeared at the age of 19, and his son developed the same pattern at the same age. The maternal grandmother of the man here shown was bald. (Fig. 3.)

From the two families traced definite conclusions cannot be drawn as to the inheritance of the amount of hair. Number of individual hairs and textures are probably inherited separately, the appearance of amount being dependant on both.

The families which were traced in reference to baldness show that it is inherited as a sex-limited trait. It is dominant in men, is inherited directly from father or mother to son, but is recessive in women. Apparently a duplex condition in women is necessary to bring it out. This is the same condition that Thos. R. Arkell found in the inheritance of horns in sheep. ${ }^{2}$

Partial baldness sometimes occurs in women in case there is illness in addition to a simplex inheritance. Where there is not the tendency to baldness the hair is slightly affected by poor health and sometimes falls out, but is regained upon the recovery of good health. Moreover, as has already been stated, some individuals in very poor health do not lose any hair.
In one family, unfortunately not charted, the father became very bald before he was thirty. His only son showed the exact pattern of his father's baldness at birth. The only hair on the head was in a fringe above the ears and at the back. Later hair came in on the top of the head, presenting a normal appearance. The boy is now nineteen years old and is beginning to lose hair above the forehead. This seems to indicate that the pattern is present at birth.

Congenital baldness must not be confused with pattern baldness. In the former there is no hair whatever, eyebrows are lacking and nails are poor or faulty. Instead of hair there is sometimes a downy fuzz. One family observed has shown this trait for the three generations about which anything is definitely known. The grandfather, father and mother were completely bald from birth. The seven sons and one daughter have never had any hair. The only grandchild, son of the oldest boy, also shows the same peculiar trait

"Arkell, T. R. "Some Data on the Inheritance of Horns in Sheep." New Hampshire Agricultural Experiment Station, Bull. 160, May, 1912. 


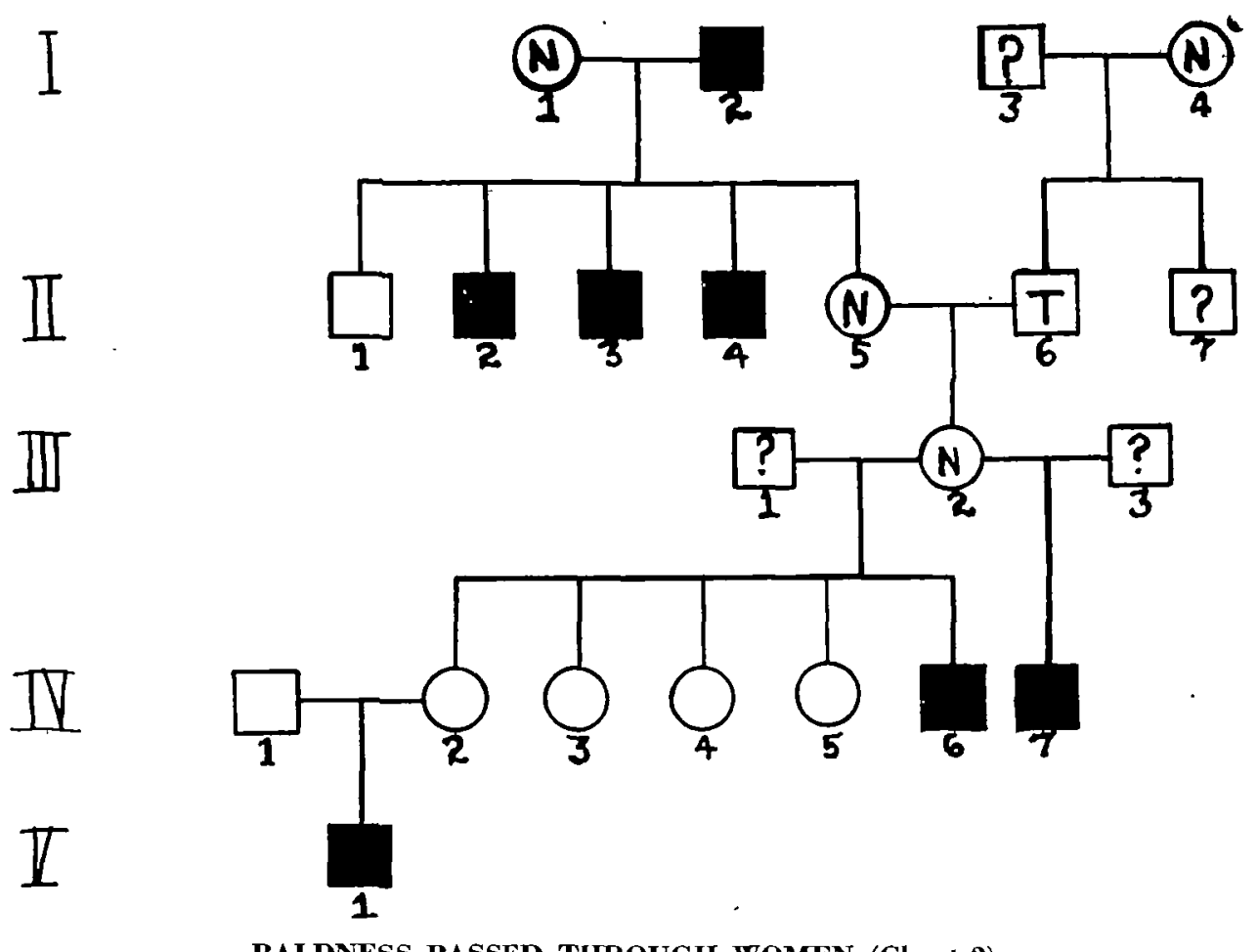

Symbols the same as in the preceding chart.

Generation I. I 1 had a normal amount of hair. I 2 was very bald but at what age is unknown. I 3 is questionable. I 4 had a normal amount.

Generation II. II 1 was not bald but amount of hair is unknown. II 2, II 3 and II 4 were all very bald but age of appearance is unknown. II 5 had a normal amount of hair. II 6 had thin hair. II 7 is questionable.

Generation III. III 1 is questionable. II 2 had a normal amount of hair but was undoubtedly a carrier, inheriting the trait from her mother who was also a carrier. III 3 is questionable.

Generation IV. IV 1 never became bald and had at least a normal amount of hair. IV 2 now past middle age, is a carrier but has never shown the trait herself. Her sisters, IV 3 , IV 4 and IV 5, have never shown any signs of baldness. IV 6 was very bald. IV 7, a half brother, was also very bald.

Generation V. V 1 became very bald between the ages of twenty-five and thirty. (Fig. 4.)

of his father's family. ' In all of these cases the nails were abnormal.

Charts 2, 3, 4 and 5 illustrate clearly the general laws of the inheritance of pattern baldness. Chart 2 is presented to show that in case a woman inherits the simplex condition she does not become bald herself, but transmits baldness, in the long run, to one-half of her sons and also the possibility of transmission to one-half of her daughters. A bald man with a simplex inheritance transmits in the same way. I 1 had a normal amount of hair, but may have been a carrier. I 2 was bald. Three out of four sons of this mating,
II 2 , II 3 , and II 4 , were all bald, and the only daughter, II 5, was probably a carrier. Her husband, II 6, was never bald. The daughter of this couple, III 2, inherited the trait from her mother and transmitted it to two sons, IV 6 and IV 7 , and, at least, one daughter, IV 2. She was married twice but as nothing is known in reference to the hair of either husband, and moreover, as a son by each marriage was bald, it was concluded that the trait was inherited through her. IV 1 was never bald, so could not transmit baldness. IV 2 must be a carrier, transmitting the trait to her son, $\mathrm{V} 1$. 
In chart 3 the trait is inherited for four generations, directly from father to son. II 5 became very bald at forty, as did both of his sons, III 5 and III 6, and also his grandson, IV 4 . In the families charted, where the inheritance is direct from father to son, the pattern and age of appearance vary slightly in succeeding generations. In this case in chart 3 baldness covers the entire top of the head and extends down almost to the neck. The hair is lost at about forty years of age. II 8 inherited baldness from his father, I 2, but accurate information could not be secured. IV 1, a woman, has a bald spot at the back of her head. Her father, III 4, was bald and her mother, III 3, was a carrier, inheriting the trait from her father, II 1 . The daughter, IV 1, inherits a duplex condition, as both parents transmit the trait. Neither of her sisters, IV 2 and IV 3 , is bald. The expectation of baldness in the daughters from a mating of this description would be one in four.

Chart 4 shows many interesting conditions. I 2 became bald at rather an early age and had quite an extensive pattern. Her four sons, II 3 and II 4, by the first, and II 6 and II 8 , by the second marriage, were all bald. Unfortunately little is known of the first two, but the two latter showed the same pattern as their mother. Having all of her sons bald would indicate that she herself was homozygous for the trait. In the families studied this holds good for two of the other three bald women, who married and had sons. The fourth bald woman, not charted, had typhoid fever when she was forty and afterwards lost the hair on the front of her head. Her father was bald. Five of her nine sons were certainly bald, two are questionable, and two were not. This is a case of baldness in a woman caused by ill health in addition to an inherited tendency. Returning to chart 4, II 5 was bald, inheriting only the simplex condition, but upon inquiry it was ascertained that she had poor health all of her life and did not become bald until rather late. Her sister, II 9, may also have been bald, but data concerning her are too uncertain to put her down as such. Her two sons, III 15 and III 16, were both bald. II 2 must be a carrier, as one son, III 9, is bald and one daughter, III 3 , is a carrier, transmitting the trait to one son, IV 2 . III 9 is bald and III 10 is a carrier, as is shown by the amount of baldness in their children.

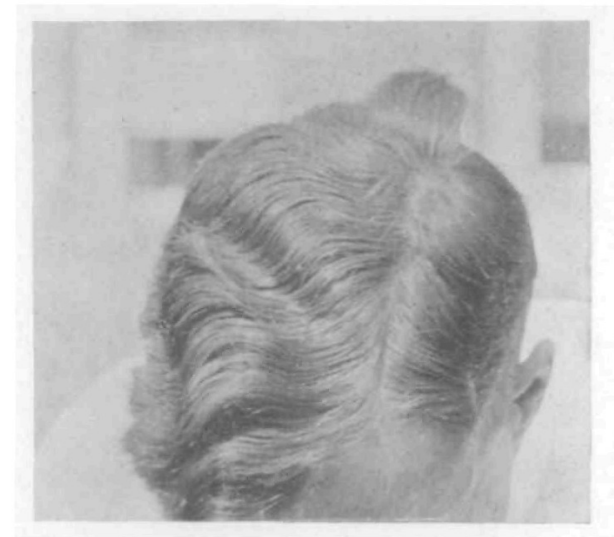

HIS BROTHERS ARE BALD

This individual, age 31 , has a heavy head of coarse hair. His two younger brothers are bald-one at the age of 22. His father is bald but his mother's family showed no baldness. The individual here shown evidently did not inherit the bald pattern, and therefore retains his hair in spite of the fact that he has had typhoid fever and other illness, and therefore has had every chance to express the inheritance if he had it. Obviously, baldness is a segregating character which may go to some of a family, but not to all unless it comes from both sides of the ancestry. (Fig. 5.)

Four sons, IV 8, IV 9, IV 12, and IV 13 , are all bald. The other two sons, IV 14 and IV 15 , are still too young to show whether they have inherited the trait or not. A daughter, IV 10, has recently become bald. She inherits the duplex condition because both of her parents transmit the trait. Another daughter, IV 11, shows no signs of baldness.

In chart 5 there is shown an unusual number of bald women. I 1 was completely bald; I 2 is questionable; II 2 was partly bald; while II 3 and II 4 were completely bald. II 1, husband 


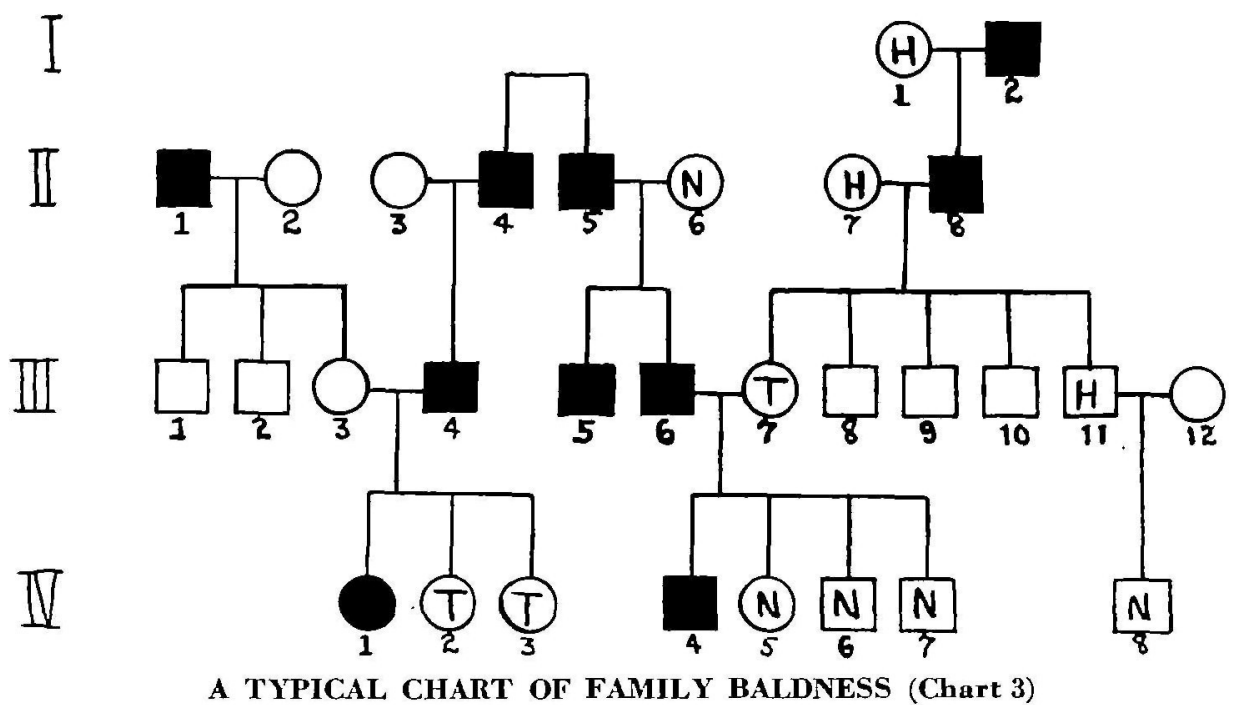

Generation I. I 1 had heavy hair. I 2 was bald.

Generation II. II 1 was bald. II 2 is unknown. II 3 is also unknown. II 4 was bald. II 5 became very bald at forty. II 6 was not bald but her family history is unknown. II 7 had heavy hair. II 8 was bald.

Generation III. III 1 and III 2 died in infancy. III 3 was not bald herself but was a carrier. III 4 was bald. III 5 and III 6 both became bald at forty, showing the same pattern as their father. III 7 had thin hair. III 8, III 9 and III 10 are questionable. III 11 has heavy hair. III 12 is not known.

Generation IV. IV 1 has a bald spot at the back of her head. IV 2 and IV 3 both have very thin hair. IV 4 became very bald at forty, having the same pattern as his father. IV 5, IV 6 and IV 7 all have a normal amount of hair. IV 8 has a normal amount of hair. (Fig. 6.)

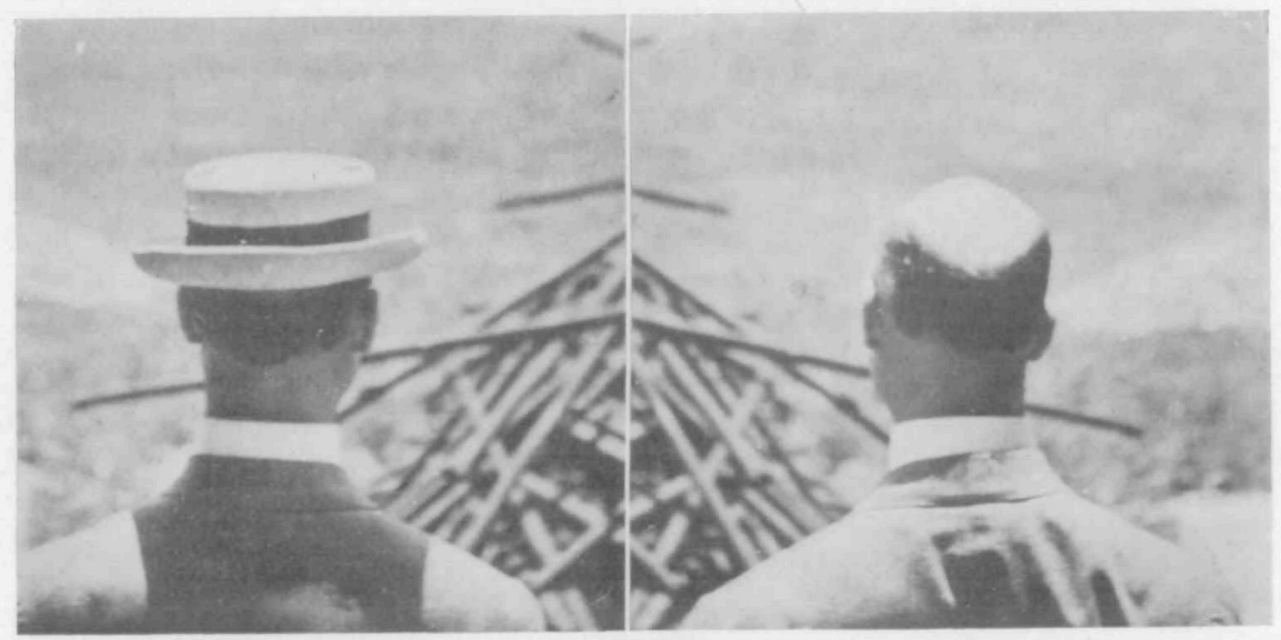

\section{THE HAT IS NOT TO BLAME}

Two views of the same individual, showing that the bald pattern is above the point where the hat binds the scalp. If baldness were due to the hat, it would be expected to begin at the line where the hat binds the head and, according to theory, cuts off the supply of blood. As a fact, the baldness is distinctly a matter of inheritance; it may appear in families where tight hats are worn; and on the other hand no amount of hat-pressure will cause it to appear in families where the hereditary determiners are not present. (Fig. 7.) 


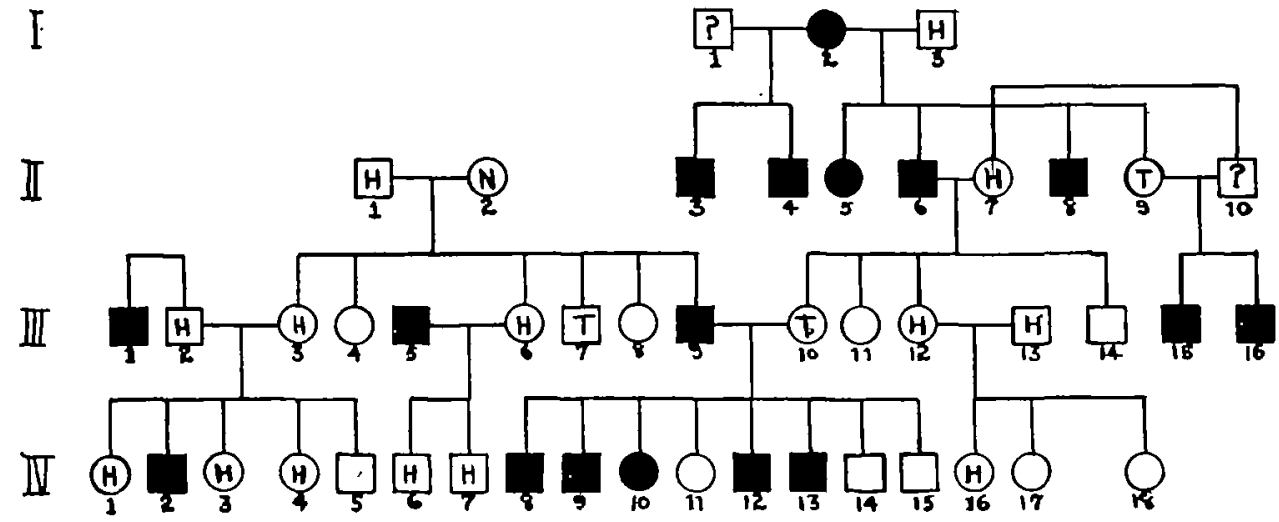

INHERITANCE OF PATTERN BALDNESS (Chart 4)

Generation I. I 1 is questionable. I 2 was very bald on the top and front of the head. I 3 had heavy hair and retained same to an advanced age.

Generation II. II 1 had heavy hair. II 2 had normal hair but was probably a carrier. II 3 and II 4 were both bald. II 5 had very poor health and was much older than the other members of her family when baldness first appeared. II 6 and II 8 were twentyfive when they first became bald and show the same pattern as their mother. II 7 had heavy hair. II 9 had very thin hair and it is thought that later in life she became bald but nothing definite concerning it is known. II 10 is questionable.

Generation III. III 1 was bald. III 2 and III 3 had heavy hair. III 4 is not known. III 5 was bald. III 6 had heavy hair. III 7 had thin hair. Nothing in reference to the hair is known about III 8 . III 9 is slightly bald. III 10 has very thin hair and is evidently a carrier. III 11 died at an early age, as did also III 14 . III 12 and III 13 had heavy hair. III 15 and III 16 both were very bald and probably became so at the same age as their uncles.

Generation IV. IV 1 had heavy hair as did also IV 3 and IV 4 . IV 2 was bald. IV 5 was not bald but the amount of hair is unknown. IV 6 and IV 7 had heavy hair. IV 8 , IV 9, IV 12 and IV 13 all became bald at about twenty-five and show the same pattern as the maternal great-grandmother. IV 10 has recently become bald, the cause assigned being illness, but the real cause is probably heredity. Both IV 14 and IV 15 are still under twenty years of age. IV 16, IV 17 and IV 18 all have heavy hair. (Fig. 8.)

TABLE I.-Inheritance in Men

\begin{tabular}{c|c|c|c|c|c|c}
\hline \multirow{2}{*}{ Matings } & \multirow{2}{*}{ No. matings } & Sons & \multicolumn{2}{|c|}{ No. bald } & \multicolumn{2}{c}{ No. not bald. } \\
\cline { 3 - 7 } & & Expectation & Actual & Expectation & Actual \\
\hline $\mathrm{BB} \times \mathrm{Bb} \ldots$ & 2 & 3 & 3 & 3 & 0 & 0 \\
\hline $\mathrm{BB} \times \mathrm{bb} \ldots$. & 5 & 13 & 13 & $\begin{array}{c}12 \\
1 ?\end{array}$ & 0 & 0 \\
\hline $\mathrm{Bb} \times \mathrm{Bb} \ldots \ldots$ & 4 & 16 & 12 & $\begin{array}{c}10 \\
2 ?\end{array}$ & 4 & 4 \\
\hline $\mathrm{Bb} \times \mathrm{bb} \ldots .$. & 49 & 108 & 54 & 64 & 54 & 44 \\
\hline $\mathrm{bb} \times \mathrm{bb} \ldots . .$. & 24 & 43 & 0 & 0 & 43 & 43 \\
\hline
\end{tabular}


Inheritance in Women

\begin{tabular}{c|c|c|c|c|c|c}
\hline \multirow{2}{*}{ Matings } & \multirow{2}{*}{ No. matings } & \multirow{2}{*}{ Girls } & \multicolumn{2}{|c|}{ No. bald } & \multicolumn{2}{|c}{ No. not bald } \\
\cline { 3 - 7 } & & & Expectation & Actual & Expectation & Actual \\
\hline $\mathrm{BB} \times \mathrm{Bb} \ldots$ & 2 & 5 & 2.5 & $\begin{array}{l}2 \\
1 ?\end{array}$ & 2.5 & 2 \\
\hline $\mathrm{BB} \times \mathrm{bb} \ldots .$. & 5 & 8 & 0 & $\begin{array}{l}1 \\
1 ?\end{array}$ & 8 & 6 \\
\hline $\mathrm{Bb} \times \mathrm{Bb} .$. & 4 & 9 & 2.25 & 2 & 6.75 & 7 \\
\hline $\mathrm{Bb} \times \mathrm{bb} . \ldots$ & 49 & 59 & 0 & 0 & 59 & 59 \\
\hline $\mathrm{bb} \times \mathrm{bb} \ldots$ & 24 & 54 & 0 & 0 & 54 & 54 \\
\hline
\end{tabular}

$B$ indicates the presence of baldness, and $b$ the absence of it.

Many of the women are carriers, but as all could not be determined no attempt was made to tabulate them separately.

The one woman of formula $\mathrm{BB} \times \mathrm{bb}$ who was bald became so through poor health in addition to a simplex inheritance.

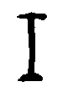

II

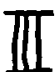

IV

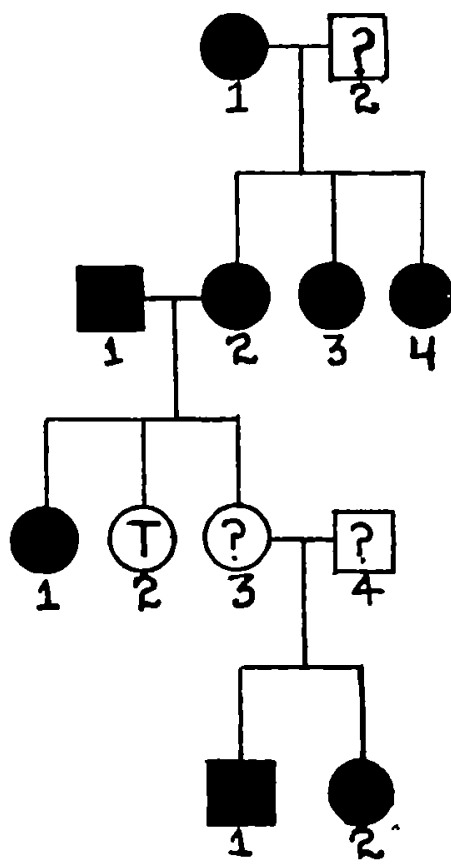

BALDNESS IN WOMEN (Chart 5)

Generation I. I 1 was completely bald. I, 2 is questionable.

Generation II. II 1 became bald at fifty-five. II 2 was partially bald. II 3 and II 4 were both completely bald.

Generation III. III 1 was completely bald became so at twenty-five. III 2 had very thin hair. III 3 is questionable, as is also III 4.

Generation IV. IV 1 has been completely bald ever since he was twenty-five. IV 2 is partially bald. (Fig. 9.) of II 2, became bald at fifty-five. In a mating of this description one-half of the daughters would probably be bald. Actually, one daughter, III 1, became completely bald at twenty-five, III 2 was never bald and III 3 is questionable. She probably became bald as both of her children, IV 1 and IV 2 , were bald. IV 1 was partly so and IV 2 became completely bald at twenty-five. Considering $\mathrm{B}$ as the presence of baldness and $b$ as the absence of it, the mating in the first generation was probably BB by BB. However it was not tabulated because of the uncertainty.

In the tabulation of the twenty-two families studied, the actual results coincide almost exactly with the expectation, except in the column marked $\mathrm{Bb}$ by $\mathrm{bb}$. The discrepancy between the number of sons and daughters exists because some families submitted did not consider any members but the men. The excess of bald men over men who are not bald can be accounted for by the fact that some of the matings were probably Bb by Bb or BB by bb. Women who are $\mathrm{Bb}$ cannot be distinguished from $\mathrm{bb}$. They were all considered $\mathrm{bb}$ unless definitely known to have male relatives who were bald. Men BB for the trait are no different from those who are $\mathrm{Bb}$. Consequently all bald men were recorded as $\mathrm{Bb}$.

While the study is not complete 
these are the conclusions that can be drawn from the work already done.

Baldness is inherited as a dominant character from father to son, and may be transmitted through the mother though she is not bald. A man who does not show baldness himself cannot transmit it to his children.

Baldness behaves as a recessive in women, appearing only when the inheritance is duplex. It is a sexlimited trait. This explains why baldness is uncommon in women, but also explains the few existing cases.

Some women become partly bald through illness in addition to an inherited (simplex) tendency.

The other theories advanced as to the cause of baldness are not satisfactory. Diseases of the scalp cannot explain pattern baldness. Very heavy hair is often associated with entire baldness on the top of the head.

Illness explains a few cases, but cannot explain the great prevalence of baldness. It does not explain why some individuals in extremely poor health retain heavy hair, and many healthy people become bald. In case baldness is due to poor health there is also an hereditary tendency.

Pressure on the scalp, as an explanation, is unsatisfactory. Many men wear tight hats which do not affect the persistence of the hair. A few of the bald men in the families studied had worn tight hats, but the majority had carefully avoided them. Contrary to the main argument in support of this theory women do become bald. It is an uncommon occurrence, but the charts readily explain that. Few people realize that the condition exists because women can conceal their baldness much more easily than men.

These theories do not agree, and none in itself is satisfactory. Heredity as a cause of baldness explains away these difficulties. It explains the presence of a pattern, why healthy individuals are afflicted, and why it is so common in men and exceptional in women.

\section{The Nassau County Survey}

The eugenic survey of Nassau County, Long Island, New York, which was described in the May issue of this journal, is well under way. It consists essentially of an examination of selected persons in all parts of the county, and all persons in selected parts of the county. The first object is to find the amount of mental defect in the community; the second is to get a picture of the eugenic constitution of the community, showing the economic productivity, health, and fertility of various sections. The director of the survey is Dr. A. J. Rosanoff, of Kings Park State Hospital, and the general supervision is in a committee, made up as follows: Dr. Charles B. Davenport, director of the Eugenics Record Office, chairman; Prof. Stephen P. Duggan, Professor of Education,
New York City College; Elizabeth E. Farrell, Inspector of Ungraded Classes, New York City Public Schools; Homer Folks, secretary, State Charities Aid Association, New York City; Dr. Thomas W. Salmon, medical director, National Committee for Mental $\mathrm{Hy}$ giene, New York City; Dr. August Hoch, director Psychiatric Institute, Ward's Island, N. Y.

The American Genetic Association feels that such research work as this is the most important contribution that can be made to eugenics at the present time. As a mark of this appreciation, the above-mentioned members of the survey committee have been added to the research committee on eugenics, of this association, for the current year. Dr. Davenport has been for many years secretary of this committee. 